\title{
Nonosmotic Diabetic Cataracts
}

\author{
JOHN I. MALONE, SAUL LOWITT, AND WILLIAM R. COOK \\ Department of Pediatrics and Diabetes Center, University of South Florida, College of Medicine, \\ Tampa, Florida 33612
}

\begin{abstract}
It has been suggested that sugar cataracts associated with diabetes mellitus result from the accumulation of excess sorbitol within lens fibrils. Swelling of lens fibrils occurs when water moves in to maintain osmotic balance; the excess water causes disruption of fibrils and cataract formation. Other studies have indicated that more than sorbitol-induced osmotic stress is involved. Our study used lenses collected from rats after 21 or $44 \mathrm{~d}$ of streptozotocin diabetes. Cataracts formed in untreated 44-d streptozotocin diabetic rats, but were not apparent in the 21-d untreated diabetic animals. Lens sorbitol increased in the diabetic animals both before and after cataract formation. Lens taurine varied inversely with the sorbitol content in a fashion that resulted in no net change in total lens osmoles. Lens water did not increase in the diabetic animals with or without cataracts. The aldose reductase inhibitor Sorbinil prevented the increase in lens sorbitol in both the 21- and 44-d streptozotocin diabetic rats; cataract formation was prevented in the 44-d diabetic animals. The lens water in untreated diabetic animals with cataracts did not differ from lens water in the Sorbinil-treated diabetic animals that did not develop cataracts. Sorbinil treatment of diabetic animals was associated with normalization of both lens sorbitol and taurine levels. Taurine has been shown to serve both as an osmoregulator and as an antioxidant. The apparent increase in lens osmolality attributed to sorbitol was counterbalanced by an equimolar reduction in taurine concentration. The reciprocal relationship between taurine and sorbitol reduces the likelihood of an osmotic mechanism for sugar cataractogenesis; the reduced lens taurine, however, may increase the risk of lens protein oxidation and subsequent cataract formation. Thus in vivo sugar cataract formation may be an oxidative process rather than an osmotic phenomenon. (Pediatr Res 27: 293-296, 1990)
\end{abstract}

Abbreviations

STZ, streptozotocin

Histopathologic studies have shown that sugar cataracts follow the swelling and rupture of lens fibers (1). Van Heyningen was the first to report that polyols (sugar alcohols) are present in excess concentrations in the lenses of animals with sugar cataracts (2). The intracellular polyol levels are the direct result of elevated sugar (glucose or galactose) concentrations that increase the activity of the polyol pathway. Inasmuch as cell membranes are relatively impermeable to sugar alcohols, the polyols accumulate intracellularly. It was subsequently reported that intracellular polyol accumulation was accompanied by increased lens water

Correspondence John I. Malone, M.D., Box 15, College of Medicine, University of South Florida, Tampa, FL 33612-4799.

Supported in part by the Health Program Office, Health and Rehabilitative Services, State of Florida, Diabetes Center Grant.
$(3,4)$ that caused swelling (termed the vacuolar stage) and subsequent disruption of the lens fibrils. The loss of lens fiber integrity is noted grossly as an opacity or cataract (5).

Animals made hyperglycemic with STZ have been shown to develop lens fiber swelling in $3 \mathrm{wk}$ and nuclear cataracts by $6 \mathrm{wk}$ (6). STZ-diabetic rats untreated with insulin commonly maintain blood glucose values greater than $22.5 \mathrm{mM}$, have massive polyuria, and do not gain weight in a normal fashion (7). These animals have the required hyperglycemia to develop cataracts; they also appear to be severely dehydrated despite special care to provide abundant water at all times.

Taurine, the most abundant free amino acid in mammalian tissues, has been noted to maintain cell volume by compensating for changes in osmotically active intracellular substances (8). It has been reported that hypernatremic dehydration causes shifts of intra- and extracellular taurine in a fashion that maintains the osmotic balance in animal tissues $(9,10)$. In addition to osmoregulation, taurine has been shown to have other cellular functions. One of these is as an antioxidant, where taurine inhibits light-induced lipid peroxidation in the frog retina (11) and retinol-induced damage in human lymphoblastoid cells (12).

Chylack and coworkers $(13,14)$ have reported that oxidative stress plays a major role in the pathogenesis of senile cataracts. It has also been noted that lens taurine decreases with increasing age and that taurine levels in senile cataracts are lower than found in noncataractous lenses of the same age $(15,16)$.

Recent reports indicate that oxidative damage is major contributor to sugar-induced cataractogenesis $(17,18)$ that can be prevented by antioxidants such as vitamin $E(19,20)$ glutathione (21), and butylated hydroxytoluene (18). Current theory about oxidative stress in the pathogenesis of sugar-induced cataractogenesis focuses on the increased turnover of NADPH caused by the increased activity of the polyol pathway. Reduced NADPH availability impairs production of glutathione, an important antioxidant.

Thus sugar-induced cataractogenesis appears to be a multifactorial process combining both osmotic and oxidative factors. Inasmuch as taurine is a substance that functions both as an osmoregulator and an antioxidant we decided to evaluate the relationship between lenticular sorbitol and taurine during the evolution of cataracts in the STZ-diabetic rat.

\section{MATERIALS AND METHODS}

Experimental diabetes was induced in fasted 60-d-old male Wistar rats (Charles River, Wilmington, NC) by the intraperitoneal injection of STZ $(65 \mathrm{mg} / \mathrm{kg})$ dissolved in cold $0.1 \mathrm{mM}$ sodium citrate buffer ( $\mathrm{pH}$ 4.5). The STZ (Sigma Chemical Company, St. Louis, MO) was dissolved in the buffer less than $20 \mathrm{~s}$ before injection. Citrate buffer was administered i.p. to control animals. Blood was collected on two or more occasions after STZ administration for the measurement of glucose concentration by a glucose oxidase method.

Seven d after STZ injection, one-half of the hyperglycemic group were given the aldose reductase inhibitor Sorbinil (Pfizer Inc., Groton, CT) $(10 \mathrm{mg} / \mathrm{kg})$ intraperitoneal daily for $37 \mathrm{~d}$ (first 
study) and $14 \mathrm{~d}$ (second study) while the other hyperglycemic rats were given vehicle alone. The Sorbinil was dissolved in a buffered isotonic sodium chloride solution $(\mathrm{pH} \mathrm{9.5)} \mathrm{and} \mathrm{the}$ concentration adjusted to $4 \mathrm{mg} / \mathrm{mL}$ and a final $\mathrm{pH}$ 7.4. The animals were provided abundant food and water and were weighed every $3 \mathrm{rd} \mathrm{d}$. The animals were examined with a flashlight every $3 \mathrm{rd} \mathrm{d}$ in a darkened room for lenticular opacities. The animal was said to have a cataract when a central opacity corresponding to stage III [nuclear cataract as described by Sipple (22)] was observed (Fig. 1).

Borosilicate test tubes $(12 \times 75 \mathrm{~mm})$ were preweighed for the collection of the rat lenses. Sodium pentobarbital $(85 \mathrm{mg} / \mathrm{kg})$ was given intraperitoneally as a general anesthetic; while the animals were alive, the lenses were removed, blotted dry, placed in the preweighed test tubes, weighed, flash frozen with liquid nitrogen, and stored at $-80^{\circ} \mathrm{C}$. The tubes containing the frozen
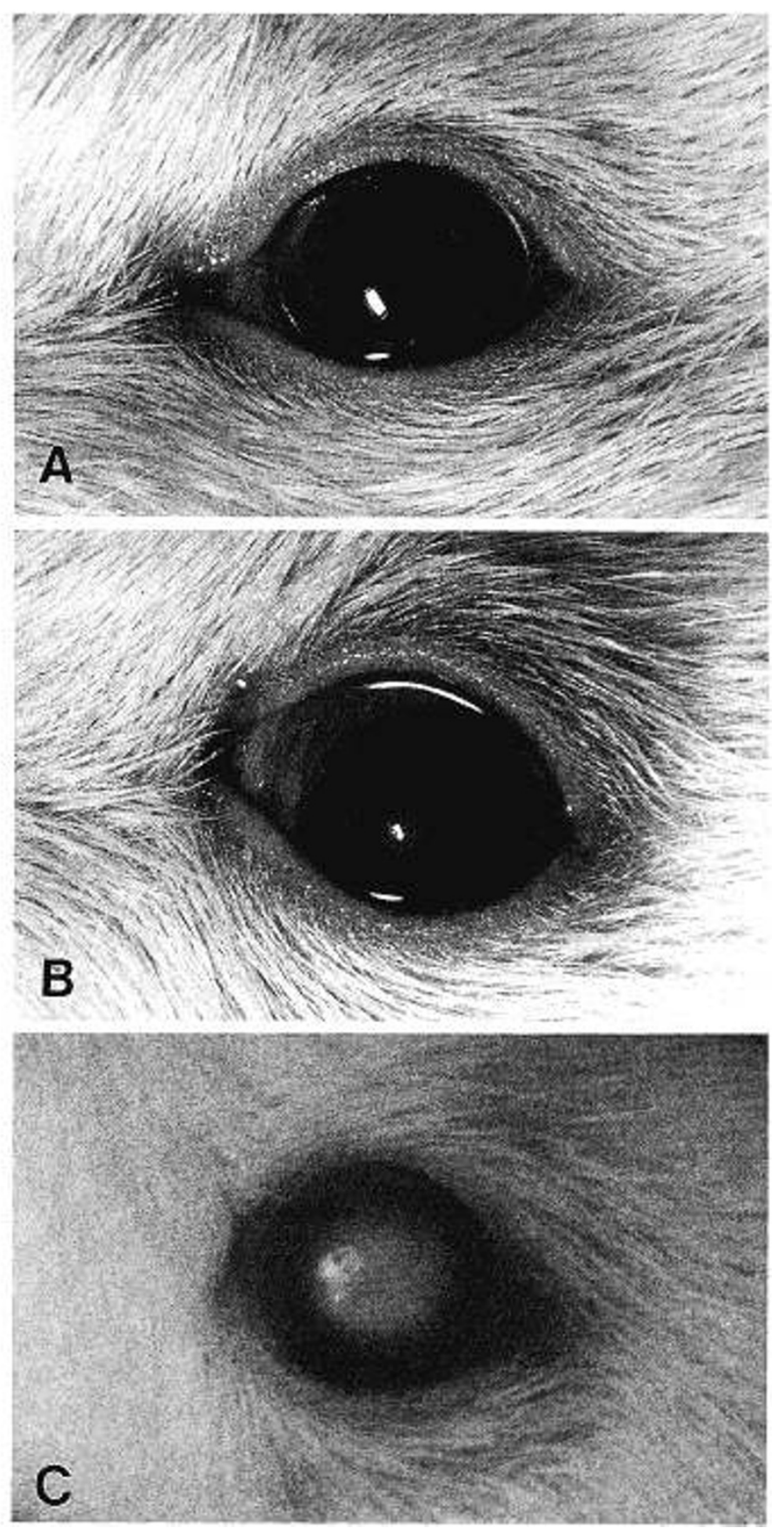

Fig. 1. $A$, transparent rat lens. $B$, nuclear opacity $(44 \mathrm{~d}) . C$, total opacification $(60 \mathrm{~d})$. lenses were lyophilized for $48 \mathrm{~h}$ and reweighed. Drying for 72 and $96 \mathrm{~h}$ did not change the dry weights. Lens water is expressed as a hydration index $\left(\mathrm{mm} \mathrm{H}_{2} \mathrm{O} / \mathrm{mg}\right.$ dry wt $\left.\times 10\right)(23)$.

The dried lenses were homogenized in $3.5 \mathrm{~mL}$ of deionized water with a motor driven ground glass homogenizer. SomogyiNelson protein free filtrates were prepared (24) and lyophilized before derivatization with acetic anhydride (25). Acetate derivatives of lens polyols were identified and quantitated on a PerkinElmer (Norwalk, CT) model 900 gas-liquid chromatograph equipped with a DB-225 Megabore column (J \& W Scientific Company, Folsom, CA) with $\alpha$-methylmannoside used as the internal standard.

Taurine concentrations were determined in protein free filtrates by HPLC utilizing a $6 \times 250 \mathrm{~mm}$ column containing 17 $\mu \mathrm{m}$ Aminex A-6 (Bio-Rad Laboratories, Richmond, CA) eluting with a citrate buffer ( $\mathrm{pH}$ 3.0) and using $o$-phthaldialdehyde (Sigma) as the indicator reagent. A fluorometer with an excitation wave length of $360 \mathrm{~nm}$ and emission wave length of $560 \mathrm{~nm}$ was used to detect amino acid peaks that were analyzed by a PerkinElmer LC-100 integrator. Serum osmolality was determined with a Precision System, Inc. (Sudbury, MA) Micro Osmette model 5004 freezing point depression osmometer.

Statistical analyses were performed on an IBM 3033 computer using the VM/CMS operating system and SAS (SAS Institute, Cary, NC) statistical programs. Analysis of variance coupled with Duncan's new multiple range test were used to detect mean differences among three or more treatment groups. Differences between two group means were detected by using the Student's $t$ test. Prudent precautions were used to avoid type I errors (26). Results are expressed as mean $\pm \mathrm{SD}$.

\section{RESULTS}

The initial study lasted for $44 \mathrm{~d}$ after the induction of hyperglycemia by STZ. During that interval the control animals gained a mean of $153 \mathrm{~g}$; the hyperglycemic animals gained a mean of $35 \mathrm{~g}$ (Table 1). The wt gain of Sorbinil-treated animals was not statistically different from the wt gain of diabetic animals not treated with the aldose reductase inhibitor (Table 1). The untreated diabetic animals began to develop cataracts at $40 \mathrm{~d}$ of

Table 1. Rat physical features

\begin{tabular}{|c|c|c|c|c|}
\hline & \multicolumn{4}{|c|}{ Streptozotocin diabetic rats $(21 \mathrm{~d})$} \\
\hline & $\begin{array}{c}\mathrm{Wt} \\
\text { (grams) }\end{array}$ & $\begin{array}{l}\text { Mean serum } \\
\text { glucose } \\
(\mathrm{mM})\end{array}$ & $\begin{array}{c}\text { Lens } \\
\text { hydration } \\
\text { index }\end{array}$ & $\begin{array}{c}\text { Serum } \\
\text { osmolality } \\
\text { (mosmol/ } \\
\mathrm{kg} \text { ) }\end{array}$ \\
\hline \multicolumn{5}{|l|}{ Control } \\
\hline Initial & $231.4 \pm 5.1$ & & & \\
\hline Final & $345.8 \pm 8.7$ & $3.5 \pm 0.7$ & $5.63 \pm 0.60$ & $296 \pm 9.8$ \\
\hline \multicolumn{5}{|l|}{ Diabetic } \\
\hline Initial & $231.8 \pm 9.0$ & & & \\
\hline Final & $228.7 \pm 19.4$ & $22.2 \pm 1.8^{*}$ & $5.20 \pm 1.20$ & $318 \pm 10.1 \dagger$ \\
\hline \multicolumn{5}{|l|}{ Sorbinil } \\
\hline Initial & $235.7 \pm 5.9$ & & & \\
\hline \multirow[t]{2}{*}{ Final } & $225.2 \pm 13.8$ & $21.5 \pm 2.4^{*}$ & $5.20 \pm 1.50$ & $311 \pm 7.5 \dagger$ \\
\hline & \multicolumn{4}{|c|}{ Streptozotocin diabetic rats (44 d) } \\
\hline \multicolumn{5}{|l|}{ Control } \\
\hline Initial & $230.7 \pm 9.3$ & & & \\
\hline Final & $383.8 \pm 17.6$ & $7.8 \pm 0.8$ & $4.92 \pm 1.20$ & $293 \pm 2.0$ \\
\hline \multicolumn{5}{|l|}{ Diabetic } \\
\hline Initial & $234.3 \pm 15.3$ & & & \\
\hline Final & $255.7 \pm 27.2$ & $27.6 \pm 4.3^{*}$ & $4.75 \pm 0.67$ & $312 \pm 2.0^{*}$ \\
\hline \multicolumn{5}{|l|}{ Sorbinil } \\
\hline Initial & $227.1 \pm 13.6$ & & & \\
\hline Final & $278.8 \pm 66.2$ & $27.4 \pm 4.7 \dagger$ & $4.00 \pm 0.69$ & $306 \pm 1.5 \dagger$ \\
\hline
\end{tabular}

$*$ Different from control $p<0.001$.

$\dagger$ Different from control $p<0.01$. 
hyperglycemia and by $43 \mathrm{~d}$ all six had cataracts, whereas none of the Sorbinil-treated nor any of the control animals showed opacification of the lens (Table 2). Sorbitol values were higher in the lenses of the diabetic animals than the controls but approached control levels in the lenses of diabetic animals treated with Sorbinil. Taurine and sorbitol concentrations varied inversely within a similar range in both the diabetic and the Sorbinil-treated diabetic animals (Table 2). The serum osmolality in the diabetic animals (with or without Sorbinil) was significantly more than control animals (Table 1). Lens water content did not increase either before or after cataract formation associated with hyperglycemia (Table 1); lens water after cataract formation did not differ from the water content of lens removed from STZ hyperglycemic rats treated with Sorbinil to prevent cataract formation. Lens wet wt and dry wt were not different for control, diabetic, or Sorbinil-treated diabetic animals (data not shown).

This study was repeated with a second group of animals after 3 wk of STZ-induced hyperglycemia. The diabetic animals did not regain their pre-STZ wt (Table 1) and appeared to be dehydrated even though excess drinking water was available. At the time of death, the serum osmolality was significantly higher in the diabetic animals (with or without Sorbinil) than in the control animals. Again, lens water in the STZ diabetic rat did not differ from control rats and was not influenced by Sorbinil treatment (Table 1). Sorbitol increased in the lens of the diabetic animals but was normal in the diabetic animals treated with Sorbinil (Table 2); taurine levels in the lens varied inversely with the sorbitol levels. Lens inositol levels were significantly reduced in the diabetic animals, increased in those animals treated with Sorbinil but did not return to control inositol levels after 2 wk of Sorbinil treatment (Table 2).

\section{DISCUSSION}

We were able, as have others, to demonstrate sugar cataract formation in the STZ hyperglycemic rat; cataracts did not form in diabetic animals receiving the aldose reductase inhibitor Sorbinil (27-29). Lens sorbitol content was four to six times higher in the STZ diabetic rats both before and after lenticular opacification than in control animals; lens taurine concentration varied inversely to sorbitol with a 3- to 7-fold reduction. Kinoshita et al. (30) also found reductions in total free amino content of lenses after cataract formation; this was thought to reflect the loss of cellular integrity. We observed a reduction of lens taurine before lens fibril disruption and a return to normal after Sorbinil treatment. Inasmuch as taurine is not linked in a metabolic fashion to the activity of the polyol pathway, its inverse relation-

Table 2. Lens chemical features

Lens sorbitol, inositol, and taurine in STZ-diabetic rats $(21 \mathrm{~d})$

\begin{tabular}{cccc}
\hline $\begin{array}{c}\text { Sorbitol } \\
(\mu \mathrm{M} / \mathrm{g} \text { dry wt })\end{array}$ & $\begin{array}{c}\text { Taurine } \\
(\mu \mathrm{M} / \mathrm{g} \text { dry wt })\end{array}$ & $\begin{array}{c}\text { Inositol } \\
(\mu \mathrm{mol} / \mathrm{g} \text { dry wt })\end{array}$ & $\begin{array}{c}\text { Cataract } \\
\text { occurrence }\end{array}$ \\
\hline $2.12 \pm 3.3$ & $15.56 \pm 2.3$ & $0.68 \pm 0.1$ & $(0 / 8)$ \\
$13.39 \pm 3.5^{*}$ & $4.96 \pm 2.1^{*}$ & $0.01 \pm 0.01^{*}$ & $(0 / 9)$ \\
$3.80 \pm 1.7 \dagger$ & $10.96 \pm 2.6 \dagger$ & $0.11 \pm 0.1 \dagger$ & $(0 / 10)$
\end{tabular}

Lens sorbitol and taurine in STZ rats (44 d)

\begin{tabular}{|c|c|c|c|}
\hline & $\begin{array}{c}\text { Sorbitol } \\
(\mu \mathrm{M} / \mathrm{g} \text { dry wt })\end{array}$ & $\begin{array}{c}\text { Taurine } \\
(\mu \mathrm{mol} / \mathrm{g} \text { dry wt })\end{array}$ & $\begin{array}{c}\text { Cataract } \\
\text { occurrence }\end{array}$ \\
\hline Control & $3.66 \pm 0.38$ & $12.90 \pm 1.10$ & $(0 / 6)$ \\
\hline Diabetic & $13.36 \pm 1.85^{*}$ & $1.83 \pm 0.54^{*}$ & $(6 / 6)$ \\
\hline Sorbinil & $4.59 \pm 3.23 \dagger$ & $11.60 \pm 1.38 \dagger$ & $(0 / 6)$ \\
\hline
\end{tabular}

* Different from control $p<0.001$.

$\uparrow$ Different from diabetic $p<0.001$. ship to sorbitol suggests a process that maintains the intracellular osmotic balance. It has been reported that changes in intracellular taurine concentration are mediated by the activity of a sodiumdependent taurine pump (31). The inverse relationship between intracellular taurine and sorbitol in hyperglycemic animals of 21 and $44 \mathrm{~d}$ indicates that the system controlling intracellular osmolality continues to operate during the evolution of the sugar cataract. Inositol, a cyclic hexatol believed to play a role in hyperglycemic tissue damage (32), normally has an intracellular gradient maintained by a sodium-dependent pump (33). This study as well as others (34) show that intracellular inositol also varies inversely with sorbitol levels in the lens of the STZ diabetic rat. The reciuced intracellular inositol found in lens of STZ diabetic rats has been attributed to impaired $\left(\mathrm{Na}^{+}, \mathrm{K}^{+}\right)$-ATPase activity (35). Inositol levels in the lens of the 21-d STZ diabetic rats varied directly with the taurine levels but the inositol concentration was so small that it was not considered to be a significant lens osmol. The quantitative changes of sorbitol, taurine, and inositol content (Table 2) in the lens of the STZ diabetic rat when summed did not differ from the total mosmol contributed by these substances in the normal lens of control animals. The significant reduction in lens inositol found in the STZ diabetic rats may be secondary to normal changes in energy dependent pump activity required to maintain a normal osmotic gradient.

The in vitro studies of Kinoshita et al. (5) indicated that movement of excess water into lens fibrils was in response to increased intracellular dulcitol; the extra water caused cellular swelling and later disruption recognized as lenticular opacification. However, others have failed to show any net increase in lens water before cataract formation $(23,36)$; Mizuno et al. (37) reported increased water content in the lens cortex near the equator during the evolution of sugar cataracts. This regionalized swelling was attributed to localization of aldose reductase to specific areas of the lens (38), which caused a localized increase of intracellular sorbitol and therefore increased cell water mediated by an osmotic mechanism. Our observation that lens taurine is reduced proportionately to the increased sorbitol suggests that the changes in taurine concentration are likely to occur in the lens areas of increased sorbitol. The lens fibril swelling that has been reported may not have an osmotic mechanism. The lens water did not increase in these STZ diabetic rats during the evolution or at the time of cataract formation. If one considers that no change occurred in lens osmolality as the result of sorbitol accumulation whereas the extracellular osmolality increased 18 to 22 mosmol in response to the osmotic diuresis of hyperglycemia it seems unlikely that water would move from the extracellular space of increased osmolality into the lens of the same or reduced osmolality.

Although osmotic stress has long been held accountable for sugar-induced cataracts, evidence is accumulating to support an oxidative mechanism for this process (17-21). Reduced taurine levels $(15,16)$ have been reported to be associated with human senile cataracts which have an "oxidative stress" etiology (13). One of the functions of taurine may be to protect lens protein from oxidative damage. Taurine concentrations in human lenses with senile cataracts are $73 \%$ lower than in noncataractus human lenses of similar age (15). Taurine levels in the lens of $21-$ and 44-d STZ diabetic rats were 68 and $85 \%$ lower than found in the lenses of control animals. The reduction of taurine, to preserve intracellular osmolality during polyol accumulation, may be sufficient to allow oxidative damage of lens fibrils. The cellular swelling noted in the lens during the evolution of the sugarinduced cataract (28) may represent the movement of water across cell membranes injured by an oxidative mechanism, rather than a net increase in lens water in response to increased intracellular osmoles.

Thus, sugar cataract and senile cataract formation may have a common, nonosmotic, final pathway that is associated with reduced lens taurine concentrations. 
Acknowledgment. The authors thank Pfizer Inc. for supplying us with Sorbinil for this study.

\section{REFERENCES}

1. Friedenwald JS, Rytel D 1955 Contribution to the histopathology of cataracts. Arch Ophthalmol 53:825-833

2. Van Heyningen R 1959 Formation of polyols by the lens of rats with sugar cataracts. Nature 184:194-196

3. Kinoshita JH 1974 Mechanisms initiating cataract formation. Invest Ophthalmol 13:713-724

4. Chylack Jr LT, Kinoshita JH 1969 A biochemical evaluation of a cataract induced in high-glucose medium. Invest Ophthalmol 8:401-412

5. Kinoshita JH, Merola LO 1964 Hydration of the lens during the development of galactose cataracts. Invest Ophthalmol 3:577-584

6. Kinoshita JH, Kador P, Catiles M 1981 Aldose reductase in diabetic cataracts. JAMA 246:257-261

7. Malone JI, Leavengood H, Peterson M, O'Brian M, Page M, Aldinger C 1984 Red blood cell sorbitol as an indicator of polyol pathway activity; Inhibition by Sorbinil in insulin-dependent diabetic subjects. Diabetes 33:45-49

8. van Gelder NM, Barbeau A 1985 The osmoregulatory function of taurine and glutamic acid. In: Oja SS, Ahtee L (eds) Taurine: Biological Actions and Clinical Perspectives. Alan R. Liss, Inc., New York, pp 149-163

9. Chan PH, Fishman RA 1979 Elevation of rat brain amino acids, ammonia and idiogenic osmoles induced by hyperosmolality. Brain Res 161:293-301

10. Trachtman H, Barbour R, Sturman JA, Finberg L 1988 Taurine and osmoregulation: Taurine is a cerebral osmoprotective molecule in chronic hypernatremic dehydration. Pediatr Res 23:35-39

11. Pasantes-Morales H, Cruz C 1985 Taurine and Hypotaurine inhibit lightinduced lipid peroxidation and protect rod outer segment structure. Brain Res 330:154-157

12. Pasantes-Morales H, Wright CE, Gaull GE 1984 Protective effect of taurine zinc and tocopherol on retinol-induced damage in human lymphoblastoid cells. J Nutr 114:2256-2261

13. Chylak LT 1984 Mechanisms of senile cataract formation. Ophthalmology 91:596-602

14. Barnett PA, Gonzalez G, Chylack LT, Cheng HM 1986 The effect of oxidation on sorbitol pathway kinetics. Diabetes 35:426-432

15. Gupta K, Mathur RL 1983 Distribution of taurine in the crystalline lens of vertebrate species and in cataractogenesis. Exp Eye Res 37:379-384

16. Auriccho G, Rinaldi E, Savastano S, Albini L, Curto A, Landolfo V 1980 The $\mathrm{Na}-\mathrm{K}-\mathrm{ATPase}$ in relation to the $\mathrm{Na}, \mathrm{K}$, and taurine levels in the senile cataract. Metab Pediatr Ophthalmol 4:15-17

17. Cheng HM, Gonzalez RG 1986 The effect of high glucose and oxidative stress on lens metabolism, aldose reductase, and senile cataractogenesis. Metabolism 35(suppl 1):10-14

18. Srivastava SK, Ansari NH 1988 Prevention of sugar induced cataractogenesis in rats by butylated hydroxytoluene. Diabetes 37:1505-1508

19. Ross WM, Creighton MO, Stewart-Dehaan PT, Sanwal M, Hirst M, Trevithick
JR 1982 Modeling cortical cataractogenesis: 3. In vivo effects of vitamin E on cataractogenesis in diabetic rats. Can J Ophtalmol 17:61-66

20. Trevithick JR, Creighton MO, Ross WM, Stewart-Dehaan PT, Sanwal M 1981 Modeling cortical cataractogenesis: 2 . In vitro effects on the lens of agents preventing glucose and sorbitol induced cataracts. Can J Ophthalmol 16:3238

21. Ross WM, Crieghton MO, Trevithick JR, Stewart-Dehaan PT, Sanwal M 1983 Modeling cortical cataractogenesis: VI: Induction by glucose in vitro or in diabetic rats prevention and reversal by glutathione. Exp Eye Res 37:559573

22. Sipple TO 1966 Changes in the water protein and glutathione contents of the lens in the course of galactose cataract development in rats. Invest Ophthalmol 5:568-575

23. Kuriyama H, Susaki K, Fukuda M 1983 Studies on diabetic cataract in rats induced by streptozotocin, II. Biochemical evaluations of rat lenses in relation to cataract stages. Ophthalmic Res 15:191-197

24. Somogyi M 1945 Determination of blood sugar. J Biol Chem 160:69-72

25. Pfaffenberger CD, Szafrankek J, Horning EC 1976 Gas chromatographic study of free polyols and aldoses in cataractus human lens tissue. J Chromatogr 126:535-545

26. Hofacker CF 1983 Abuse of statistical packages: The case of the general linear model. Am J Physiol 245:R299-R302

27. Peterson MJ, Sarges R, Aldinger CE, MacDonald DP CP-45,634 1979 A novel aldose reductase inhibitor that inhibits polyol pathway activity in diabetic and galactosemic rats. Metabolism 28:456-461

28. Beyer-Mears A, Kelly K, Cruz E 1985 Synergism of sorbinil and normal diet on reversal of stage-II sugar cataract. Pharmacology 31:170-179

29. Unakar NJ, Tsui JY 1983 Inhibition of glactose-induced alterations in ocular lens with sorbinil. Exp Eye Res 36:685-694

30. Kinoshita JH, Barber GW, Merola LO, Tung B 1969 Changes in the levels of free amino acids and myo-inositol in the galactose-exposed lens. Invest Ophthalmol 8:625-632

31. Chesney R, Gusowski N, Dabbagh S, Padilla M 1985 Renal cortex taurine concentration regulates renal adaptive response to altered dietary intake of sulfur amino acids. In: Oja SS, Ahtee L (eds) Taurine: Biological Actions and Clinical Perspectives. Alan R. Liss, Inc, New York, pp 33-42

32. Finegold D, Lattimer SA, Nolle S, Bernstein M, Greene DA 1983 Polyol pathway activity and myo-inositol metabolism: a suggested relationship in the pathogenesis of diabetic neuropathy. Diabetes 32:988-992

33. Yorek MA, Dunlap JA, Ginsberg BH 1986 Myoinositol uptake by four cultured mammalian cell lines. Arch Biochem Biophy 246:801-807

34. Kinoshita JH 1986 Aldose reductase in the diabetic eye. Am J Ophthalmol 102:685-692

35. Beyer-Mears A, Cruz E 1985 Reversal of diabetic cataract by sorbinil, an aldose reductase inhibitor. Diabetes 34:15-21

36. Patterson JW, Bunting KW 1965 Changes associated with the appearance of mature cataracts. Invest Ophthalmol 4:167-173

37. Mizuno A, Nozawa H, Yaginuma T, Matsuzaki H, Ozaki Y, Iriyama K 1987 Effect of aldose reductase inhibition on experimental diabetic cataract monitored by laser raman spectroscopy. Exp Eye Res 45:185-186

38. Akagi Y, Yajima Y, Kador PF, Kuwabara T, Kinoshita JH 1984 Localization of aldose reductase in the human eye. Diabetes 33:562-566 